\title{
ABNORMAL P WAVES AND PAROXYSMAL TACHYCARDIA
}

\author{
BY \\ L. G. DAVIES* AND I. P. ROSS $\dagger$ \\ From The National Heart Hospital, London \\ Received January 28, 1963
}

Specific changes in the $\mathrm{P}$ wave of the electrocardiogram have been recognized in mitral stenosis (Lewis and Gilder, 1912), pulmonary heart disease (Winternitz, 1935), left ventricular failure (Wood and Selzer, 1939), and congenital heart disease (Paul, Myers, and Campbell, 1951). These changes are believed to be the result of right or left atrial hypertrophy (Reynolds, 1953; Thomas, and Dejong, 1954). We have noticed $P$ wave abnormalities in some patients with paroxysmal tachycardia, an observation that does not appear to have been reported by other workers. In our patients the abnormal $P$ waves were prolonged, usually to 0.12 second or more, and were frequently notched. These abnormalities were not due to any of the recognized causes for these hearts were clinically normal. As a pilot study 50 electrocardiograms from patients with paroxysmal tachycardia and 50 from normal controls were mixed together and studied independently by four observers. The results confirmed our preliminary observations and we decided to study a larger series.

\section{SubJECTS AND Methods}

We examined the records of patients in whom a firm clinical diagnosis of paroxysmal tachycardia had been made. Those patients with organic heart disease were excluded, so were a number with normal hearts where the electrocardiograms were unsatisfactory because of sinus tachycardia or tremor. The series therefore consisted of $\mathbf{2 0 0}$ patients where the clinical record and electrocardiogram were suitable for analysis.

The routine electrocardiograms between attacks had been taken with a Cambridge string-galvanometer electrocardiograph with a speed of $25 \mathrm{~mm}$. a second and 0.20 and $0.04 \mathrm{sec}$. time markings. The instrument used is important, for the $\mathbf{P}$ wave abnormalities are less easily seen on tracings obtained with direct writing machines. In some of these patients a paroxysm had been observed and a record obtained. Tracings taken from 100 patients with normal hearts provided a control series.

The electrocardiograms were examined in a good light with a large magnifying glass. Both observers had to agree before a $\mathbf{P}$ wave was recorded as abnormal. Detailed observations on the $\mathbf{P}$ waves included duration, which was measured along the lower margin of the base line, height, presence of notching, interval between peaks, and the P-R interval. The relation between $\mathbf{P}$ wave and $\mathbf{P}-\mathbf{R}$ interval was calculated by the method of Macruz, Perloff, and Case (1958). The $P$ wave vector was analysed in respect of magnitude and direction.

\section{RESULTS}

Description of Abnormal $P$ Waves. Fig. 1 shows 8 examples of the abnormal $P$ waves seen in these patients. The main points are increased duration, usually to $0.12 \mathrm{sec}$, , and notching which is sometimes very striking. The Ta wave may be prominent, as with enlarged $\mathbf{P}$ waves due to other causes. All these abnormalities are best seen in standard lead II. We found that 43 of our 200 patients showed these abnormal $P$ waves. The details are given in Table I, and for comparison, the results in the control series of 100 patients with normal hearts.

* Present address: Sully Hospital, Penarth, Glamorgan.

+ Present address: The London Hospital, London E.1. 

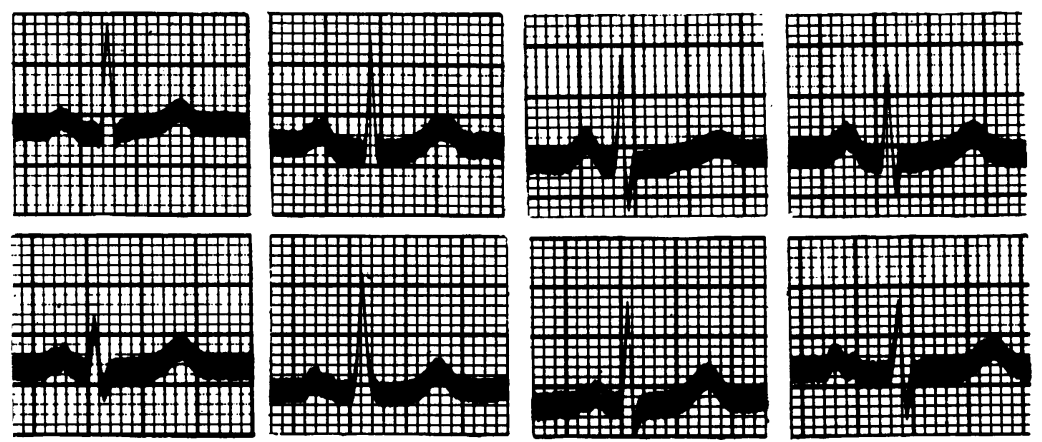

FIG. 1.-Lead II from 8 patients with paroxysmal tachycardia and a normal heart.

The $\mathbf{P}$ waves all show increased duration and some are bifid.

TABLE I

Detalls of Abnormal P Waves in 43 Patients with Paroxysmal Tachycardia and the FINDINGS IN 100 NORMAL SUBJECTS

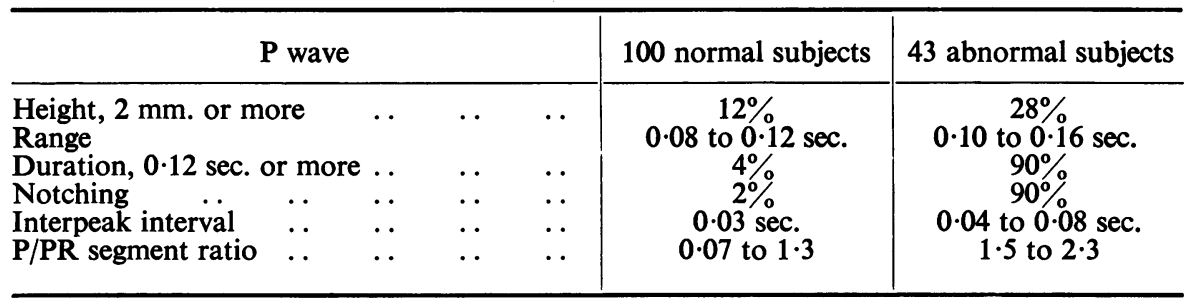

TABLE II

Comparison of the Incidence of Abnormal P Waves in Patients with Paroxysmal Atrial Fibrillation and THOSE WITH OTHER SUPRAVENTRICULAR TACHYCARDIAS

\begin{tabular}{|c|c|c|c|c|}
\hline Arrhythmia & Normal P wave & Abnormal $\mathbf{P}$ wave & Total & $\begin{array}{c}\text { Incidence } \\
(\%)\end{array}$ \\
\hline $\begin{array}{l}\text { Atrial fibrillation } \\
\text { Supraventricular tachycardia } \\
\text { Total .. .. . . }\end{array}$ & $\begin{array}{r}34 \\
123 \\
157\end{array}$ & $\begin{array}{l}10 \\
33 \\
43\end{array}$ & $\begin{array}{r}44 \\
156 \\
200\end{array}$ & $\begin{array}{l}22 \cdot 7 \\
21 \cdot 1 \\
21 \cdot 5\end{array}$ \\
\hline
\end{tabular}

The increased duration, the notching with widened interpeak interval, and the raised $\mathbf{P} / \mathbf{P R}$ segment ratio, all suggest that the abnormality lies in the left atrial component of the $P$ wave.

Examination of the $P$ wave vectors revealed nothing unusual.

Incidence of Abnormal $\boldsymbol{P}$ Waves. The incidence of abnormal $\mathbf{P}$ waves in our patients with paroxysmal tachycardia was one in five. We first studied the possibility that these changes were associated with a particular type of tachycardia. The diagnosis in 44 of our 200 patients was paroxysmal atrial fibrillation, either because this rhythm had been observed or because of a history of an irregular tachycardia. The value of this historical evidence is uncertain: if it is fairly accurate, then abnormal $\mathbf{P}$ waves are as frequent in patients with paroxysmal fibrillation as in those with supraventricular tachycardia (Table II).

There is other evidence on this point, which is possibly conflicting. Electrocardiograms during 
TABLE III

P Waves in 27 Patients with Electrocardiographic Evidence of the Nature of the Tachycardia

\begin{tabular}{|c|c|c|c|c|}
\hline Arrhythmia & Normal $P$ wave & Abnormal $\mathrm{P}$ wave & Total & $\begin{array}{l}\text { Incidence of abnormal } \\
\text { P waves }(\%)\end{array}$ \\
\hline $\begin{array}{l}\text { Atrial fibrillation } \\
\text { Supraventricular tachycardia } \\
\text { Total .. . . . . }\end{array}$ & $\begin{array}{r}9 \\
7 \\
16\end{array}$ & $\begin{array}{r}9 \\
2 \\
11\end{array}$ & $\begin{array}{r}18 \\
9 \\
27\end{array}$ & $\begin{array}{l}50 \\
22 \\
40\end{array}$ \\
\hline
\end{tabular}

TABLE IV

Relation between Abnormal P Waves and Changes in the S-T Segment and T Wave AFTER TACHYCARDIA

\begin{tabular}{ccc|c|c|c}
\hline & & $\begin{array}{c}\text { ST and T changes } \\
\text { (No. of patients) }\end{array}$ & $\begin{array}{c}\text { Normal P wave } \\
\text { (No. of patients) }\end{array}$ & $\begin{array}{c}\text { Abnormal P wave } \\
\text { (No. of patients) }\end{array}$ \\
\hline $\begin{array}{c}\text { Present } \ldots \\
\text { Absent } \ldots\end{array}$ &.. &.. & 37 & 25 & 12 \\
\hline
\end{tabular}

a paroxysm were obtained in 27 of our 200 patients, and an analysis of the $P$ waves between attacks in these 27 is given in Table III. This shows that abnormal $P$ waves are much commoner in patients whose paroxysmal tachycardia is due to atrial fibrillation, but the numbers are too small to be entirely convincing. Of the nine patients with other supraventricular tachycardias, the cardiograms showed atrial tachycardia in six, and nodal tachycardia in three. Atrial flutter was recorded in one of our 200 patients, but his usual arrhythmia was paroxysmal fibrillation: his P waves were normal. It appears that abnormal $\mathbf{P}$ waves can occur with most if not all the common varieties of paroxysmal tachycardia, but the exact frequency is uncertain. The reason for this is the difficulty in obtaining cardiograms during a paroxysmal arrhythmia on patients who are not in hospital.

Association with Changes in S-T Segment and T Wave. Evidence that the abnormal $\mathrm{P}$ waves were a result of the arrhythmia was examined. We studied their relation with the changes in the S-T segment and $\mathrm{T}$ wave that sometimes follow a paroxysm of tachycardia. These changes were present in the electrocardiograms of 37 of our 200 patients (Table IV).

We found that abnormal $\mathbf{P}$ waves were twice as frequent in patients with S-T segment and T wave changes as in those without. This relation suggests that the $P$ wave abnormalities could be the result of the tachycardia. However it does no more than this, the figures are inconclusive, and moreover the S-T segment and $\mathrm{T}$ wave changes are known to be transient and variable.

Time Since Last Attack. Further evidence that might show whether the $\mathrm{P}$ wave abnormalities were the result of the arrhythmia was their relation with the interval since the last attack. The dates on which each patient attended hospital and had a cardiogram were always known, but the time of the most recent attack was recorded in less than half of our 200 patients.

In 18 of our 43 patients with abnormal $P$ waves the interval between the most recent attack and the time of examination varied between one day and eight weeks with an average of 12 days. Similar information in 69 patients with normal $P$ waves gave a range of one day to ten weeks with an average of 15 days. These intervals are not very different and in any case the ranges are wide. We can only say therefore that examination of this point shows no convincing evidence that the $\mathbf{P}$ wave abnormalities are the result of a paroxysm of tachycardia.

It is interesting, however, that we were unable to find any patient where serial tracings showed abnormal $\mathbf{P}$ waves that subsequently returned completely to normal. One reason may be that further paroxysms occurred in most patients, but in the few who had long intervals between their 
paroxysms, and where we had serial records, the duration of the $\mathrm{P}$ wave commonly remained prolonged, although some regression took place and the notching became less obvious.

Age of Patients. The average age of the 43 patients with abnormal $P$ waves was 57 years (range 23 to 84 years), while in those with normal $P$ waves it was 45 years (range 17 to 78 years).

Other factors were studied, but were found to be of similar frequency in the abnormal and normal $P$ wave groups. These included the sex incidence, the average heart rate during an attack when this was known, the average duration of the separate attacks, and the average time during which the paroxysms had been present in these patients.

\section{DisCUSSION}

Paroxysmal tachycardia is a difficult condition to study. The pathology has not been established, the factors that precipitate an attack are not fully known, we do not know what determines the natural ending of a paroxysm, and the results of drug treatment cannot be predicted with any certainty. We have found that one in five of our patients showed abnormalities of the $P$ wave in routine electrocardiograms taken between attacks but have failed to find the cause of these changes. The abnormalities appear to be due to changes in the left atrial component of the $P$ wave, but were not the result of any disorder that could be detected on clinical examination. The patients who show these changes are on average 12 years older than those who do not, but the difference in $P$ wave pattern is not the result of a longer history of attacks, for this is the same in both groups. Neither the heart rate during an attack nor the duration of the paroxysms appeared to be of any importance.

We considered the possibility of the abnormal $P$ waves being in some way the result of the paroxysm. There does seem to be some relation between $P$ wave abnormalities and the changes in the S-T segment and $\mathrm{T}$ wave that may follow a paroxysm of tachycardia; for when these were present, abnormal $P$ waves were twice as frequent as when they were not. Even then they were present only in a minority and the evidence is therefore unconvincing.

It is interesting that we could find no clear relation between abnormal $P$ waves and a particular type of arrhythmia. We had thought that the changes might result from the absence of atrial activity during a paroxysm, perhaps with functional mitral regurgitation (Daley, McMillan, and Gorlin, 1955), or alternatively that they might be a feature of nodal tachycardia where the atria contract against closed atrioventricular valves. There may of course be a relation of this kind which had not emerged because of the practical difficulty of obtaining an electrocardiogram during an attack: only in a small minority of our patients were we able to do this, and other workers have had the same difficulty (Campbell, 1947). A further point is that some patients are known to have more than one type of tachycardia and this would make the relation with abnormal $P$ waves even more difficult to establish.

a)

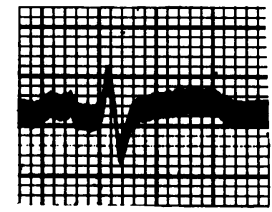

b)

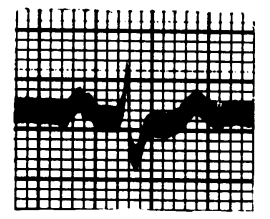

FIG. 2.-(a) Lead II from a patient with an atrial septal defect and paroxysmal tachycardia but no evidence of mitral valve disease. (b) Lead II from a patient with ischæmic heart disease and paroxysmal tachycardia.

While these theoretical aspects are of some interest, the only practical application we can claim for our observation is that the presence of an abnormal $P$ wave helps to confirm a diagnosis of paroxysmal tachycardia made, as it usually is, on the history alone. The value of the sign is somewhat diminished by the popularity of direct recording electrocardiographs.

A final point is that these $\mathbf{P}$ wave changes are also found in patients with organic heart diseases and paroxysmal tachycardia. Fig. 2 shows two examples, the first having an atrial septal defect 
without evidence of mitral valve disease, and the second ischæmic heart disease without any left ventricular failure.

\section{SUMMARY}

In routine electrocardiograms taken between attacks, abnormal $P$ waves were found in 43 of 200 patients with paroxysmal tachycardia and hearts that were clinically normal. The abnormal $P$ waves were usually seen in lead II and the main features were increased duration, usually to $0 \cdot 12$ sec., and notching, which was sometimes very striking. These features suggest that the abnormality lies in the left atrial component of the $\mathbf{P}$ wave.

There is some suggestion that these abnormalities are related to age and are the result of a paroxysm particularly when the arrhythmia is due to atrial fibrillation. The evidence on these points however is inconclusive.

No relation was found between abnormal $P$ waves and the heart rate during a paroxysm, the average duration of an attack, or the total length of history.

The presence of these abnormal $\mathbf{P}$ waves is of some value in confirming a retrospective clinical diagnosis of paroxysmal tachycardia.

We wish to thank the physicians at The National Heart Hospital for allowing us to study their patients and the late Dr. Paul Wood for much helpful advice.

\section{REFERENCES}

Campbell, M. (1947). The paroxysmal tachycardias. Lancet, 2, 641 and 681.

Daley, R., McMillan, I. K. R., and Gorlin, R. (1955). Mitral incompetence in experimental auricular fibrillation. Lancet, 2, 18.

Lewis, T., and Gilder, M. D. D. (1912). The human electrocardiogram: a preliminary investigation of young male adults, to form a basis for pathological study. Phil. Trans., 202B, 351.

Macruz, R., Perloff, J. K., and Case, R. B. (1958). A method for the electrocardiographic recognition of atrial enlargement. Circulation, 17, 882.

Paul, O., Myers, G. S., and Campbell, J. A. (1951). The electrocardiogram in congenital heart disease. Circulation, 3, 564 .

Reynolds, G. (1953). The atrial electrocardiogram in mitral stenosis. Brit. Heart J., 15, 250.

Thomas, P., and Dejong, D. (1954). The P wave in the electrocardiogram in the diagnosis of heart disease. Brit. Heart J., 16, 241.

Winternitz, M. (1935). Zur Pathologie des menschlichen Vorhofelektrokardiogramms. Med. Klin., $31,1575$.

Wood, P., and Selzer, A. (1939). A new sign of left ventricular failure. Brit. Heart J., $1,81$. 